Article

\title{
Quantifying the Climate Impact of the US Policy Choices Using an Economic and Earth System Model
}

\author{
Shili Yang ${ }^{1,2}$, Changxin Liu ${ }^{3, *}$, Wenjie Dong ${ }^{4,5, *}$, Jieming Chou ${ }^{1}$, Di Tian ${ }^{6}$, Ting Wei ${ }^{7}$ \\ and Yuan Tian ${ }^{3}$ \\ 1 State Key Laboratory of Earth Surface Process and Resource Ecology, Beijing Normal University, \\ Beijing 100875, China; yangsl@mail.bnu.edu.cn (S.Y.); choujm@bnu.edu.cn (J.C.) \\ 2 Business School, Beijing Normal University, Beijing 100875, China \\ 3 Institutes of Science and Development, Chinese Academy of Sciences, Beijing 100190, China; \\ tianyuan@casipm.ac.cn \\ 4 Atmospheric Science School, Sun Yat-Sen University, Guangzhou 510000, China \\ 5 Zhuhai Joint Innovative Center for Climate-Environment-Ecosystem, Future Earth Research Institute, \\ Beijing Normal University, Zhuhai 519087, China \\ 6 State Key Laboratory of Satellite Ocean Environment Dynamics, Second Institute of Oceanography, \\ Hangzhou 310012, China; tiandi@sio.org.cn \\ 7 Chinese Academy of Meteorological Sciences, Beijing 100081, China; weitalzu@163.com \\ * Correspondence: liuchangxin@casipm.ac.cn (C.L.); dongwj3@mail.sysu.edu.cn (W.D.); \\ Tel.: +86+136-0135-7410 (W.D.)
}

Received: 24 April 2018; Accepted: 1 June 2018; Published: 5 June 2018

\begin{abstract}
Climate policy plays an important role in keeping global temperature rises below the target of $1.5-2{ }^{\circ} \mathrm{C}$ above pre-industrial levels, and technological innovations are key to determining the effectiveness of climate policy. In this study, we investigated the climate impact of the USA's policy choices using the enforced multi-factor regional climate and economy system (EMRICES,) and the Earth system model from Beijing Normal University (BNU-ESM). Three emission scenarios were designed based on the assumption of whether or not the US follows its proposed nationally determined contribution (NDC) and makes use of technological innovations. The results showed that if the US does not implement the NDC and had no technological progress, there would be an extra 176.7 Gt of cumulative carbon emissions by the end of the 21st century compared to that of all the countries that follow their NDC. The additional emissions would lead to an increase of $62 \mathrm{ppm}$ in $\mathrm{CO}_{2}$ concentration and a $0.4{ }^{\circ} \mathrm{C}$ increase in global warming by 2100 . It would also lead to a $2 \%$ loss for the US and Chinese economies, compared to the NDC scenario. The Earth system model results also show that even if all the countries follow the DNC, it would be difficult to keep the temperature from increasing less than $1.5^{\circ} \mathrm{C}$. This study implies that the US withdrawal from the Paris Agreement and their refusal to adopt technological progress is not conducive to achieving the $1.5^{\circ} \mathrm{C}$ goal, and more stringent emission reduction targets or technology innovations would be required for the world to control global warming to a level below $1.5^{\circ} \mathrm{C}$.
\end{abstract}

Keywords: climate policy; Paris Agreement; Earth system model; economic model; climate impact

\section{Introduction}

Climate change is an interdisciplinary issue involving energy, health, policy, and other fields, and has been of great interest to scientists and the public for a long time. It is well-recognized that the temperature rise should be limited to below $1.5-2{ }^{\circ} \mathrm{C}$ above pre-industrial levels in order to avoid dangerous climate changes [1-3]. Carbon reduction is one of the key approaches to mitigate climate change, but it will affect the national energy structure and would result in certain economic costs [4]. 
However, different countries have different abilities to undertake climate change reduction. Thus, climate negotiations that provide a public platform for the discussion of how to allocate or distribute the remaining limited carbon emission fairly between governments are particularly important.

There has been great progress in recent decades, making a significant contribution to the global and regional climate mitigation and adaptation. The recent Paris Agreement adopted by 195 member countries established a global system of international cooperation addressing climate issues after 2020, and is considered to be a milestone and a new start in climate negotiations. Almost all of the parties submitted their intended nationally determined contributions (NDC) to the Paris Agreement. For example, the NDC target submitted by China commits them to reduce carbon emission intensity by $60-65 \%$ in 2030 compared to 2005, while the NDC submitted by the US reduces their carbon emissions by $26-28 \%$ in 2025 compared to 2005 . All the plans seem to be in accordance with the results of the negotiations and can lead to a better future.

However, President Donald Trump decided to withdraw from the Paris Agreement on 1 June 2017, a decision which was outside the expectations of most scientists and governments. This decision is generally believed to have the potential to affect global confidence and enthusiasm in addressing climate issues, and will have a significant impact on the effectiveness of emission reductions. Many researchers have criticized Trump's choice [5-11]; for example, some studies pointed out that Trump's decision may influence the USA's energy structure and energy innovations $[10,12,13]$. A low innovation rate may reduce the speed of carbon intensity reduction. For example, Seo [14] argues that an important role of technological progression is to protect climate. Xing, Hanaoka et al. [15] have studied the effect of energy transitions on greenhouse emissions and economic growth. Pan, Chen et al. [16] found that China's non-fossil fuel energy must account for $50-70 \%$ and $85 \%$ of the primary energy consumption in 2050 and 2100, respectively, if it is to achieve the $2{ }^{\circ} \mathrm{C}$ goal. If the USA's energy innovation declines, its carbon emissions would increase in proportion to (Gross domestic product) (GDP) growth, suggesting that the global climate may be greatly influenced by energy technology innovation. However, the consequences and quantitative impact of Trump's decision on global carbon emissions and the climate system are still unknown.

In this paper, we investigated this issue by combining an economic model of enforced multi-factor regional climate and economy system (EMRICES) and an Earth system model from Beijing Normal University (BNU-ESM). The EMRICES comprehensively covers energy and economic processes and can be used to design emission pathways, including or excluding the US NDC and technology innovation. The BNU-ESM incorporates the full ocean and land carbon cycles and is therefore closer to the real Earth system change than simple climate models. It can therefore model detailed Earth system changes under the prescribed emission pathway.

The remainder of the article is organized as follows. In Section 2, we introduce the EMRICES and BNU-ESM model and describe the emission scenario and experimental design method. Section 3 gives the results of the experiments. The conclusions and discussions are provided in the last section.

\section{Materials and Methods}

A combination of the economic model and Earth system model were used in this study, with the aim of projecting the impact of the US withdrawal from the Paris Agreement. The impact of the withdrawal on technological progress can be simulated through economic models and reflected by the emission scenario. The Earth system was forced by the emission scenario and calculated the corresponding climate, and the climate impact was then calculated by the damage function. This process overcomes the uncertainty of the emission scenario in the Earth system model and solves inadequacies of detailed climate change simulations that cannot be completed in an economic model.

\subsection{The EMRICES Model}

The EMRICES model is a general equilibrium model that divides the world into 10 regions: China, the US, Japan, the European Union, India, Russia, high-income countries, upper-middle-income 
countries, lower-middle-income countries, and low-income countries. The economic systems of these countries are connected by the regional economic linkages. In this model, the economic system in each country (or each region) is based on the macro-dynamic economic model, while China, the US, Japan, India, and Russia are accounted for by the computable general equilibrium (CGE) model. A detailed description of EMRICES can be found in Wang et al. [17].

\subsubsection{Energy Carbon Emissions Calculation}

In the EMRICES model, the global carbon emissions are the sum of the carbon emission of all the countries or regions:

$$
C(t)=\sum_{i} C_{i}(t)
$$

where $C(t)$ represents the global total carbon emissions at time $t$ and $C_{i}(t)$ represents the carbon emissions of country $i$ at time $t$.

Each country's carbon emissions are aggregated from all economic sectors:

$$
C_{i}(t)=\sum_{K=0}^{n} C_{i, j}^{s}(t)
$$

where $C_{i, j}^{S}(t)$ represents the carbon emissions of the economic sector $j$ in country $i$ at time $t$.

Each economic sector's carbon emissions are calculated by the amount of each energy type it consumes and the corresponding carbon emission parameter. The energy types include coal, oil, natural gas, and non-fossil fuel:

$$
\begin{aligned}
& C_{i, j}^{s}(t)=\sum_{k} E_{i, j, k}(t) X \beta_{k} \\
& E_{i, j, k}(t)=\delta_{i, j, k}(t) X Y_{i, j}(t)
\end{aligned}
$$

where $\delta_{i, j, k}(t)$ is the energy intensity (energy intensity equals the total energy consumption per unit GDP) of the economic sector $j$ in country $i$ at time $t$ with respect to energy $k$, which represents the energy technology level. $Y_{i, j}(t)$ is the output level of the economic sector $j$ in country $i$ at time $t$. Each country or region has its own technological innovation rate, $\beta_{k}$, which is the carbon emission parameter for energy $k$.

\subsubsection{NDC Targets}

According to the Paris Agreement, the goal of the current nationally determined contribution (NDC) for carbon emissions is to limit the surface temperature warming under $2{ }^{\circ} \mathrm{C}$ above pre-industrial levels (UNFCCC, 2015). Thus, the carbon emission scenario in this paper is calculated using the most stringent emission reduction targets put forward by each country as a NDC. For example, China's NDC target is that its carbon emission intensity (equals the total $\mathrm{CO}_{2}$ emissions per unit GDP) will drop by $60-65 \%$ in 2030 compared with that in 2005 , so we use the decline target of $65 \%$ in this paper.

Most countries' NDCs can be directly or indirectly divided into two classes. For example, the US, the EU, and others give a NDC target based on the total emission level, while China, Japan, India, and others provide a clear reduction target mainly based on carbon emission intensity. For these two different accounting methods, the following two equations were used to calculate the emissions in the target year, respectively:

$$
\begin{gathered}
\mathrm{E}_{2030}=\mathrm{E}_{2005} \times r_{c} \\
\mathrm{E}_{2030}=\mathrm{En}_{2005} \times r_{e} \times Y_{2005}
\end{gathered}
$$

where $\mathrm{E}_{2030}$ represents the carbon emission in the target year (i.e., 2030); $\mathrm{E}_{2005}$ and $\mathrm{En}_{2005}$ are the emission and emission intensity in the base year, which are taken from data provided by the World Bank; $r_{e}$ is the emission intensity decline rate provided by the NDCs; $Y_{2005}$ is the gross domestic product (GDP) under the baseline scenario; and $r_{c}$ represents the total carbon emission reduction rate. 
For high-income countries, upper-middle-income countries, lower-middle-income countries, and low-income countries, some countries in these regions have not yet submitted independent contributions (the emissions of these countries accounts for no more than $2 \%$ of the global carbon emissions) and some countries that have submitted contributions have no clear carbon emission reduction targets (such as Egypt and Bolivia). Meanwhile, there are many different emission reduction benchmark years and targets, so it is difficult to give an accurate overall value of global carbon emission reduction targets.

To solve this problem, we adopted a different approach. For high-income countries (for example, Canada, New Zealand, Australia, Norway, and Singapore), the carbon emission reduction rate of each country is about $30 \%$ compared with that in 2005 , so the total emissions in the target year are about $301.86 \mathrm{Mt} \mathrm{C}$. The NDC targets of upper-middle-income countries, lower-middle-income countries, and low-income countries are mainly based on carbon emission intensity and the emission reduction rate in the baseline scenario.

The specific NDC goals, years, and carbon emission targets in each country or region are shown in Table 1.

Table 1. The nationally determined contribution (NDC) targets and converted carbon emissions in the targets years.

\begin{tabular}{cccccc}
\hline Country & NDC Targets & Benchmark Year & Target Year & $\begin{array}{c}\text { Emission in Target } \\
\text { Year (Mt C) }\end{array}$ & $\begin{array}{c}\text { Share of Global Emission } \\
\text { in 2009 (\%) }\end{array}$ \\
\hline China & $65 \%$ & 2005 & 2030 & 3786.89 & 1169.57 \\
USA & $26 \%$ & 2005 & 2025 & 251.80 & $25.66 \%$ \\
Japan & $25.4 \%$ & 2005 & 2030 & 648.00 & $3.88 \%$ \\
The EU & $40 \%$ & 1990 & 2030 & 1170.76 & $11.55 \%$ \\
India & $35 \%$ & 2005 & 2030 & 425.83 & $5.05 \%$ \\
Russia & $25 \%$ & 1990 & 2030 & 301.86 & $5.58 \%$ \\
High-income countries & $30 \%$ & 2005 & 2030 & 1169.31 & $12.35 \%$ \\
Upper-middle-income countries & $35 \%$ & Benchmark scenario & 2030 & 739.39 & $5.04 \%$ \\
Lower-middle-income countries & $35 \%$ & Benchmark scenario & 2030 & & $0.42 \%$ \\
Low-income countries & $35 \%$ & Benchmark scenario & 2030 & & \\
\hline
\end{tabular}

\subsubsection{Scenario Design}

It is important to see what happened to carbon emissions in the years prior to the Paris Agreement. US carbon emissions declined in recent years, including a slight decrease in 2017. The reason for this is partly due to the development of green low-carbon technologies promoted by the Obama administration. A reduction in use of traditional fossil energies, especially from the coal industry, coupled with the fluctuations of the US economy, also contributed to the decline of carbon emissions. However, it was only a temporary fluctuation, not a stable trend. During the Trump administration, traditional energy sources will be developed. This means that in the near future, the energy structure of the US will not develop in the direction of low-carbon and clean energy $[18,19]$. As the US economy increases, the country is expected to continue increasing its carbon emissions. Thus, we do not think that the US carbon emissions have reached their peak.

However, due to the relatively stable industrial structure in the US, energy intensity and carbon emission intensity are at a relatively low level. If the US maintains the speed of progress in natural technologies, whether it implements NDC or not will not have a significant impact on the global carbon emissions and this needs to be accounted for in simulations.

On the other hand, it is important to find out the level of global carbon emissions if the US energy intensity and carbon intensity are affected by Trump's policies and do not maintain a downward trend.

We considered three scenarios that model the situation after the US withdrew from the Paris Agreement: (a) Noted NDC: the US and other countries follow their NDC target; (b) NDC-NA: the US does not execute its NDC target but shows progress in implementing technology changes; (c) NDC-NA-NT: the US does not execute its DNC and shows no progress in implementing new technologies. It should be mentioned that we assume that all the states will not contribute to the 
technological progress to simplify the method, though some states (e.g., California) have their own carbon reduction plan. Table 2 gives a detail description of these three scenarios.

Table 2. The NDC, NDC-NA and NDC-NA-NT scenario description.

\begin{tabular}{ccc}
\hline Name & Carbon Emission Targets & $\begin{array}{c}\text { Technology Progression in the } \\
\text { US (Energy Intensity) }\end{array}$ \\
\hline NDC & Follow NDC (the US implements) & Yes \\
NDC-NA & Follow NDC (the US does not implement) & Yes \\
NDC-NA-NT & Follow NDC (the US does not implement) & No \\
\hline
\end{tabular}

The temporal evolution of these three scenarios can be found in Figure 1. Although they have similar temporal evolution characteristics, the carbon emissions under the DNC-NA-NT scenario are significantly higher than those of the NDC and NDC-NA scenarios after 2030. There is little difference between the NDC-NA and NDC scenarios, which indicates that the decision of the US to withdraw from the Paris Agreement will have an obvious impact on global carbon emissions through slowing down technological progress. These scenarios also show that there will be a global carbon peak at around 2020, followed by a rapid decline to 2030, and then a slower reduction to 2100 . By the end of the 21st century, the cumulative carbon emissions gap between the NDC-NA-NT and the NDC scenarios is about $176.7 \mathrm{Gt} \mathrm{C}$ (gigatonnes of carbon).

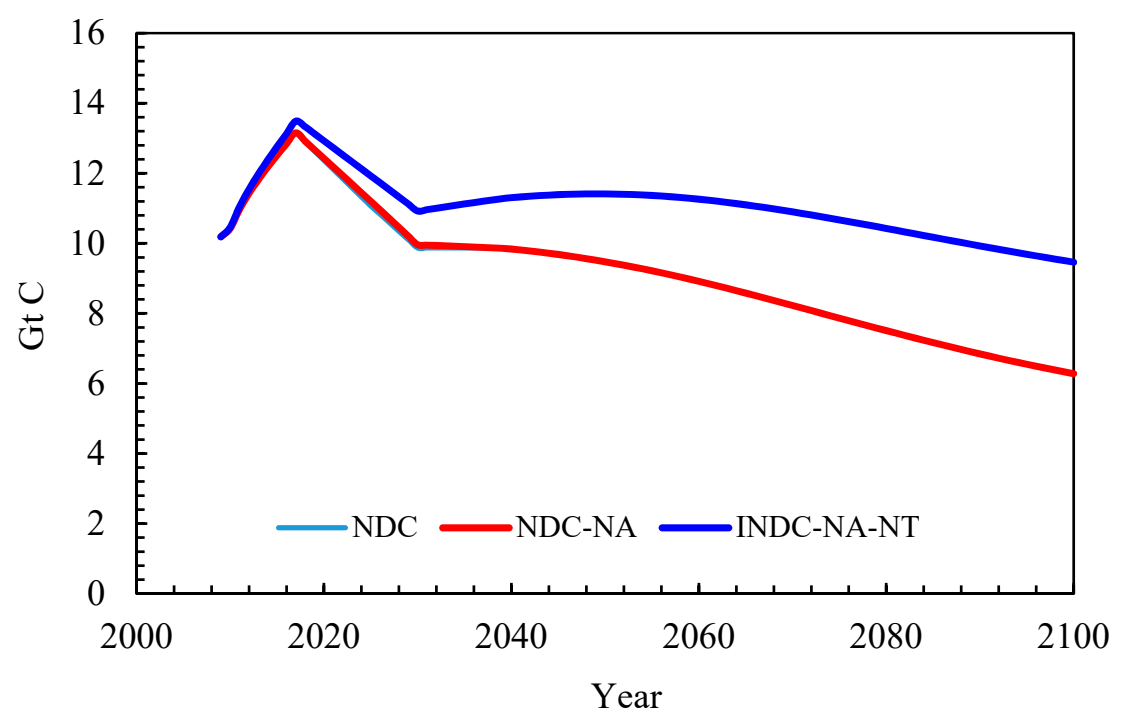

Figure 1. The changes of carbon emissions under the NDC, NDC-NA, and NDC-NA-NT scenarios.

\subsection{Earth System Model Description and Experiment Design}

\subsubsection{The BNU-ESM Model}

The BNU-ESM model is a fully coupled model developed by Beijing Normal University and is one of the models used on behalf of China participating in Coupled Model Intercomparison Project Phase 5 (CMIP5). The BNU-ESM consists of four separate components to simulate the atmosphere (CAM3.5), land (CoLM), ocean (MOM), and ice (CICE4.1). These four components are coupled by the CPL6.0 coupler, which is used to coordinate the energy and information flux between the different components. Ji et al. gave a full description of the BNU-ESM and showed that it can reproduce many basic characteristics of the Earth's climate system, such as temperature, El Niño-Southern Oscillation (ESNO), sea ice extent, etc. [20,21]. The BNU-ESM model is also widely used in climate attribution and projection [22-24]. For example, Wei et al. quantified the effects of $\mathrm{CO}_{2}$ emissions from the developed 
and developing world on historical and future climate changes [22]. We also used the results of Model for the Assessment of Greenhouse Gas Induced Climate Change (MAGICC) [25] as a reference.

\subsubsection{Data and Experiment Design}

As mentioned in Section 2.1.3, emissions under the NDC and NDC-NA scenarios have similar values, so we only designed two experiments to quantify the impact of the US climate policy on the future climate. One is the NDC experiment, resulting from the NDC scenario; and the other is the NDC-NA-NT experiment, arising from the NDC-NA-NT scenario. Quantities apart from $\mathrm{CO}_{2}$ (for example, the ozone and aerosols) were provided by the RCP4.5 [26].

It should be mentioned that these two experiments fully include the land and ocean carbon cycles. So we have to convert the annual total global carbon emissions to a monthly gridded $\mathrm{CO}_{2}$ flux (units: $\mathrm{kg} \cdot \mathrm{m}^{-2} \cdot \mathrm{s}^{-1}$ ) using the method from Yang et al. [27,28]. The gridded NDC and NDC-NA-NT scenarios have the same spatial and temporal distribution, with representative concentration pathways (RCPs).

Figure 2 gives the $\mathrm{CO}_{2}$ flux of the gridded NDC and NDC-NA-NT conditions. It is clear that the emissions are mainly distributed over East Asia, the south-east of North America, and the west of Europe.
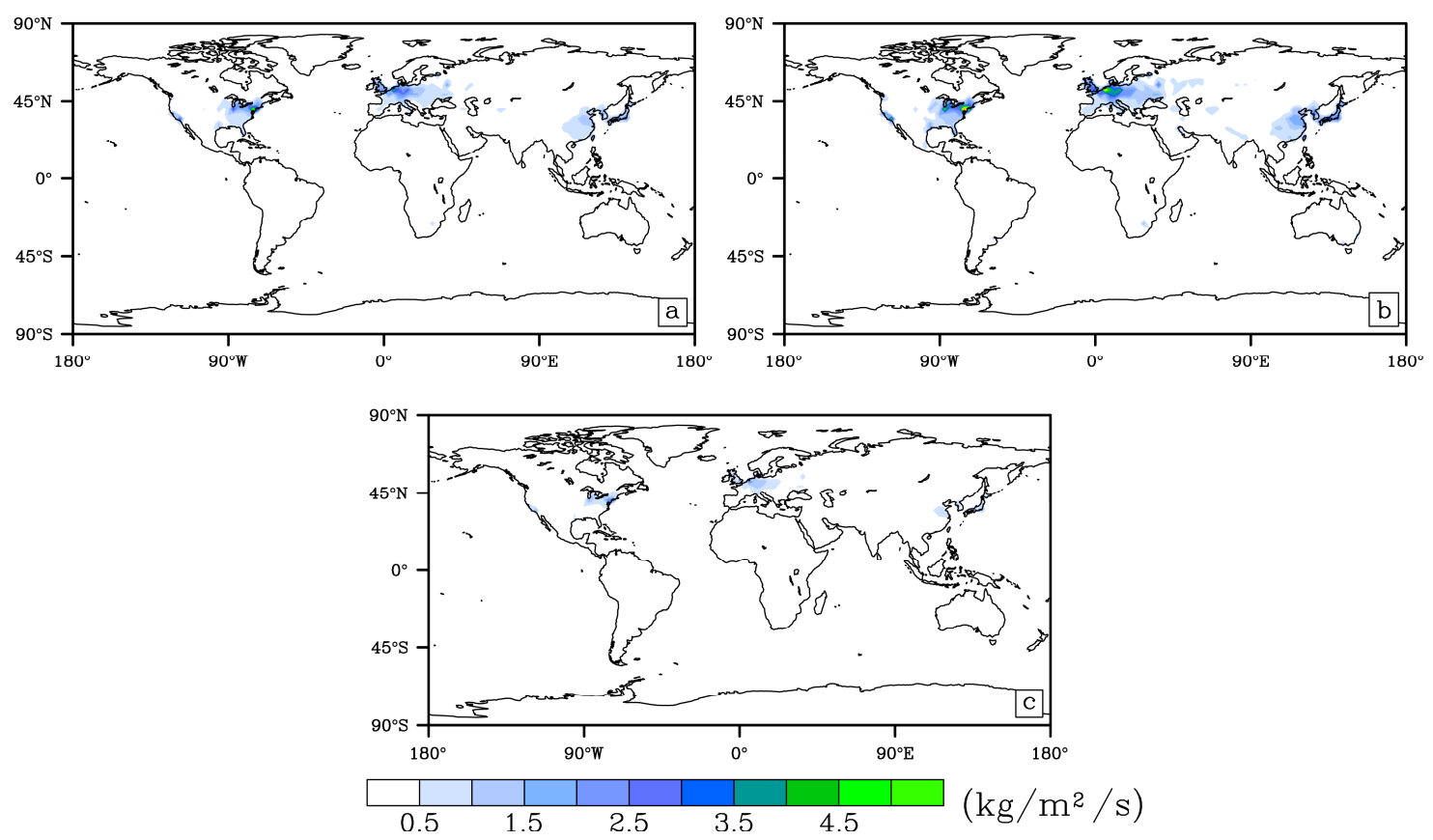

Figure 2. The gridded carbon flux and the differences for the NDC and NDC-NA-NT scenario in 2100. (a) NDC; (b) NDC-NA-NT; (c) NDC-NA-NT minus NDC.

\section{Results}

\subsection{The Global $\mathrm{CO}_{2}$ Concentration and Temperature Change}

Our results predict that the $\mathrm{CO}_{2}$ concentration will increase at a rate of $2.26 \mathrm{ppm} /$ year and $2.95 \mathrm{ppm} /$ year under the NDC and NDC-NA-NT experimental conditions, respectively. Both increase rates are in the range of RCP4.5 (1.83 ppm/year) and RCP8.5 (5.96 ppm/year), though they are much closer to that of RCP4.5. At the end of the 21st century, the $\mathrm{CO}_{2}$ concentrations of the NDC and NDC-NA-NT conditions reach $582 \mathrm{ppm}$ and $644 \mathrm{ppm}$, respectively, under the BNU-ESM model. This is higher than that of the MAGICC results. However, the $\mathrm{CO}_{2}$ gap between the NDC and NDC-NA-NT 
conditions is similar under the BNU-ESM and MAGICC models, which are about $62 \mathrm{ppm}$ and $56 \mathrm{ppm}$, respectively (Figure 3).

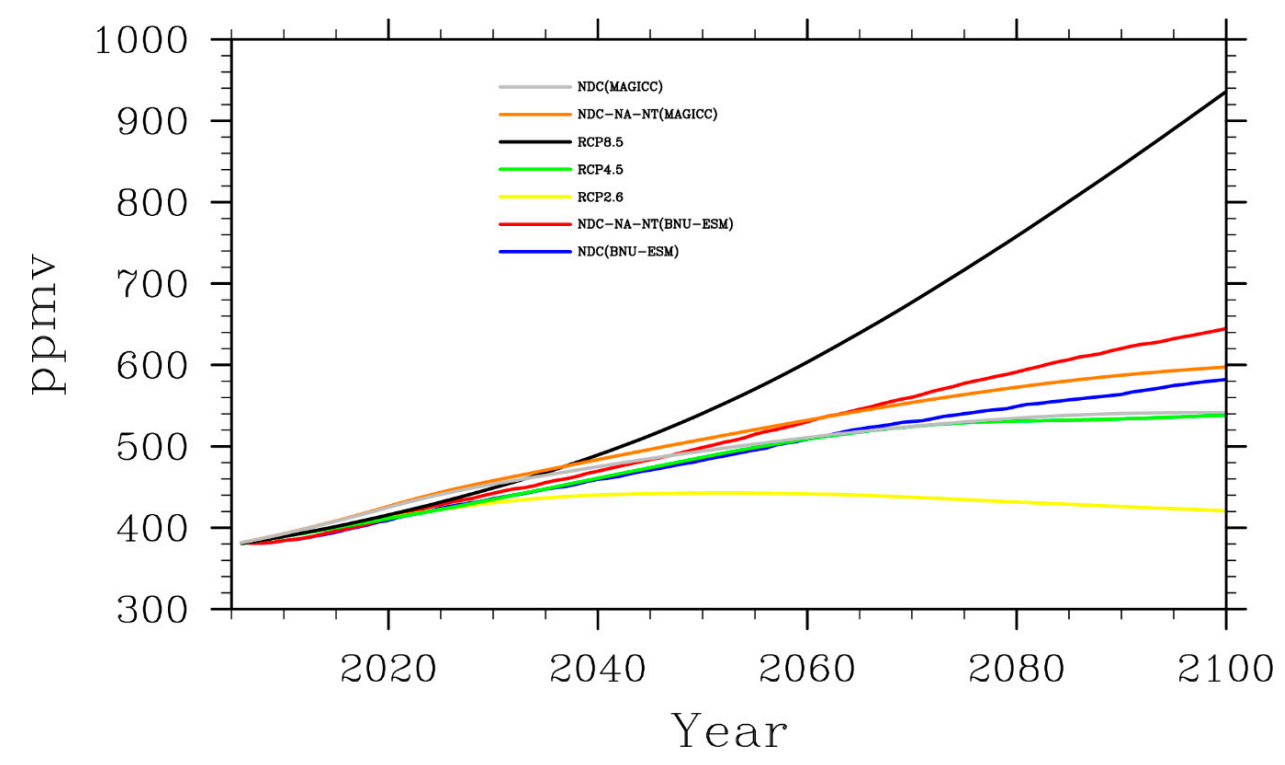

Figure 3. The $\mathrm{CO}_{2}$ concentration simulated by BNU-ESM and MAGICC under the NDC and NDC-NA-NT scenarios and representation concentration pathways (RCPs).

Figure 4 shows the time evolution of the global surface temperature of the NDC and NDC-NA-NT simulated by MAGICC and BNU-ESM, and CMIP5 multiple model simulations under representative concentration pathways (RCPs). The temperature shows a significant increasing trend under the NDC and NDC-NA-NT scenarios, with warming falling within the multiple model ensemble of RCP8.5 and RCP4.5. At the end of the 21st century (2081-2099), the temperature is projected to increase by $2.7^{\circ} \mathrm{C}$ and $3.1^{\circ} \mathrm{C}$ compared to the average of $1986-2005$, which is in the range of $\mathrm{RCP} 4.5\left(2.6^{\circ} \mathrm{C} \pm 0.8^{\circ} \mathrm{C}\right)$ and RCP8.5 $\left(5.2^{\circ} \mathrm{C} \pm 1.2^{\circ} \mathrm{C}\right)$ [29]. The warming of the NDC-NA-NT condition is about $0.4^{\circ} \mathrm{C}$ higher than that of the NDC condition, and both of these scenarios project that it is unlikely that global warming will fall below $1.5^{\circ} \mathrm{C}$ at the end of the 21st century. The spatial temperature change of the NDC and NDC-NA-NT conditions can be found in Figure 5.

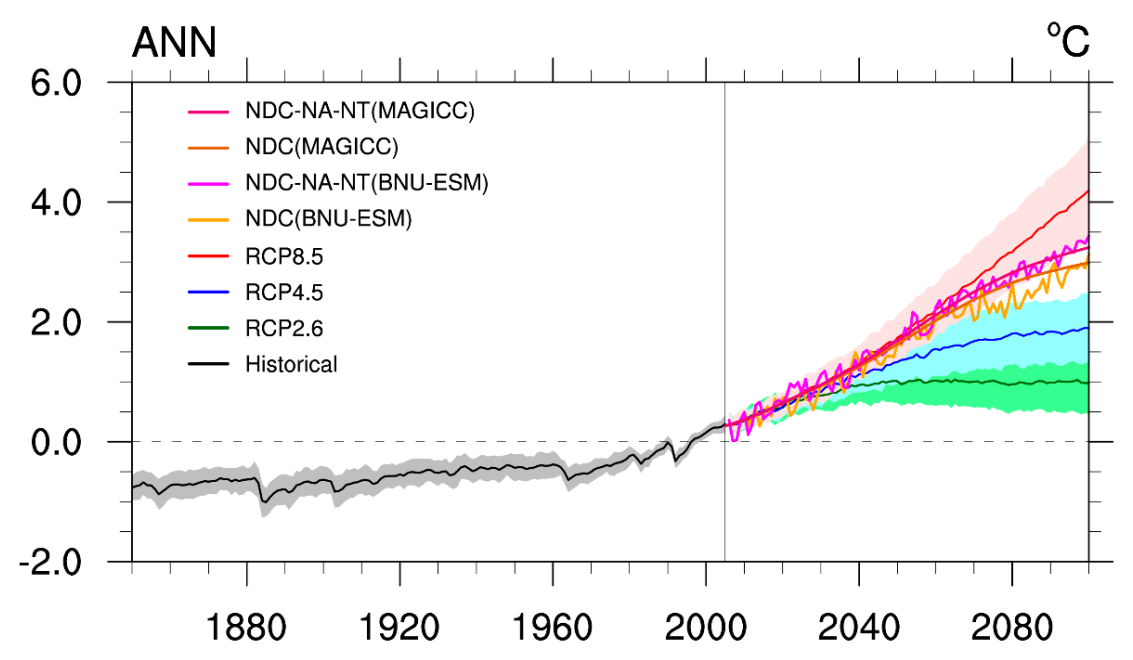

Figure 4. The surface air temperature simulated by CMIP5 multiple models and the NDC and NDC-NA-NT experiments (the anomaly is related to the average of the years from 1986 to 2005). 


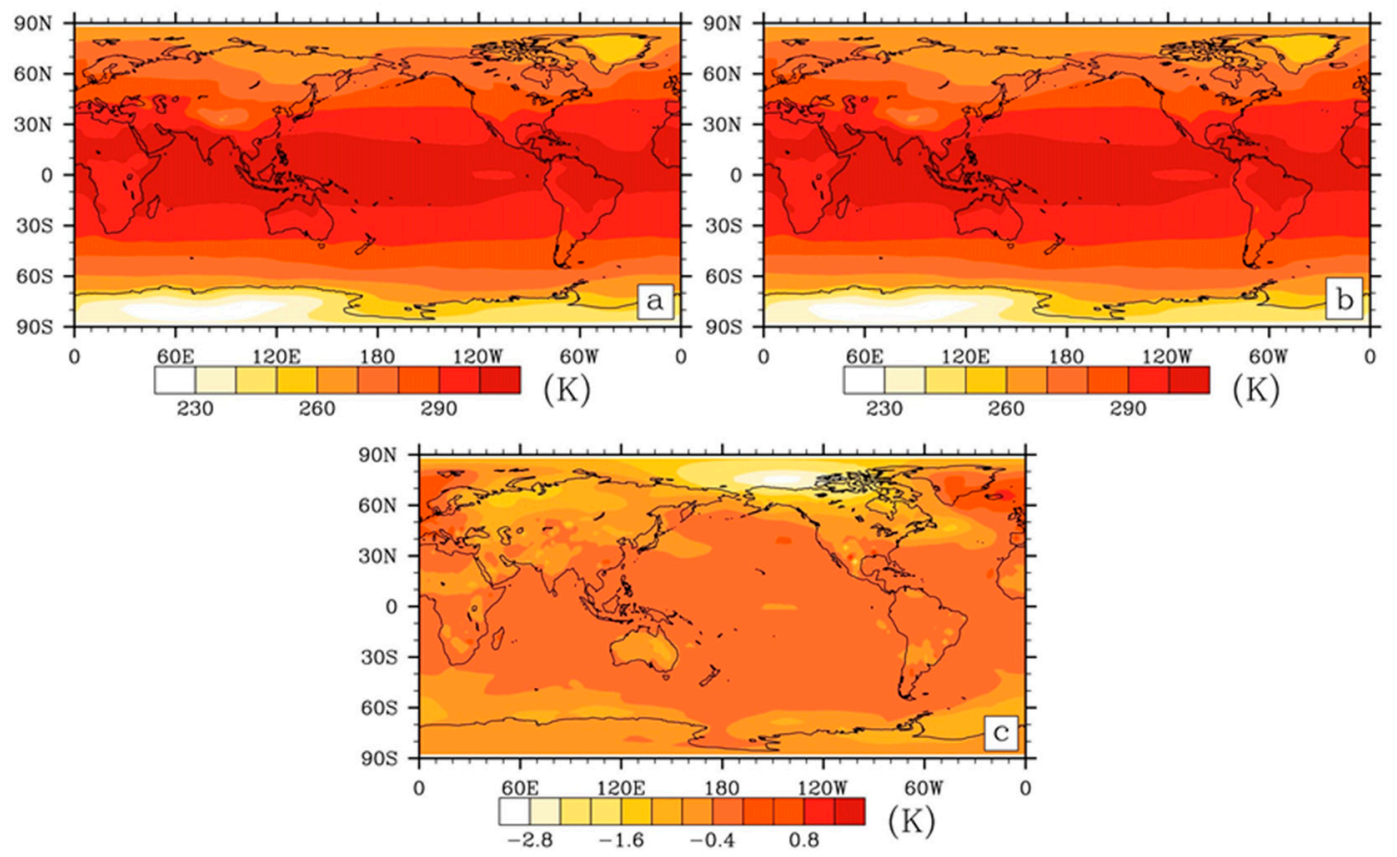

Figure 5. The simulated spatial pattern of the temperature from BNU-ESM averaged over 2080-2099: (a) NDC; (b) NDC-NA-NT; (c) NDC minus NDC-NA-NT.

\subsection{Economic Losses}

Climate change may cause serious economic losses, which toned o be adequately considered [30]. The economic impact of the two scenarios was also investigated using the damage function of climate change, which is part of the Integrated Assessment Model (IAM). The damage function from the Dynamic Integrated Model of Climate Change and Economy (DICE) [31-33] was adopted, and the result is shown in Figure 6. The equation of the climate damage function is as follows:

$$
A_{i t}=1.0-\frac{1.0}{1.0+\left(\frac{D_{i}}{9}\right) T_{t}^{2}}
$$

where $A_{i t}$ represents the ratio of the total net output (excluding the climate impact) to the theoretical total output in time $t$ over an area $i, D_{i}$ is the loss coefficient of warming over area $i$, and $T_{i}$ is the warming amplitude.

As can be seen, climate change would result in a large economic loss, which could be as high as $14 \%$ of China's GDP and $10 \%$ of the US GDP. This reveals that the US may suffer a lower climate change economic loss than China because of its better adaptive ability. The results also show that the economic loss would be lower by $2 \%$ in the NDC condition compared to the DNC-NA-NT condition, which means that the progression of technology can provide a saving of $2 \%$ of GDP. 

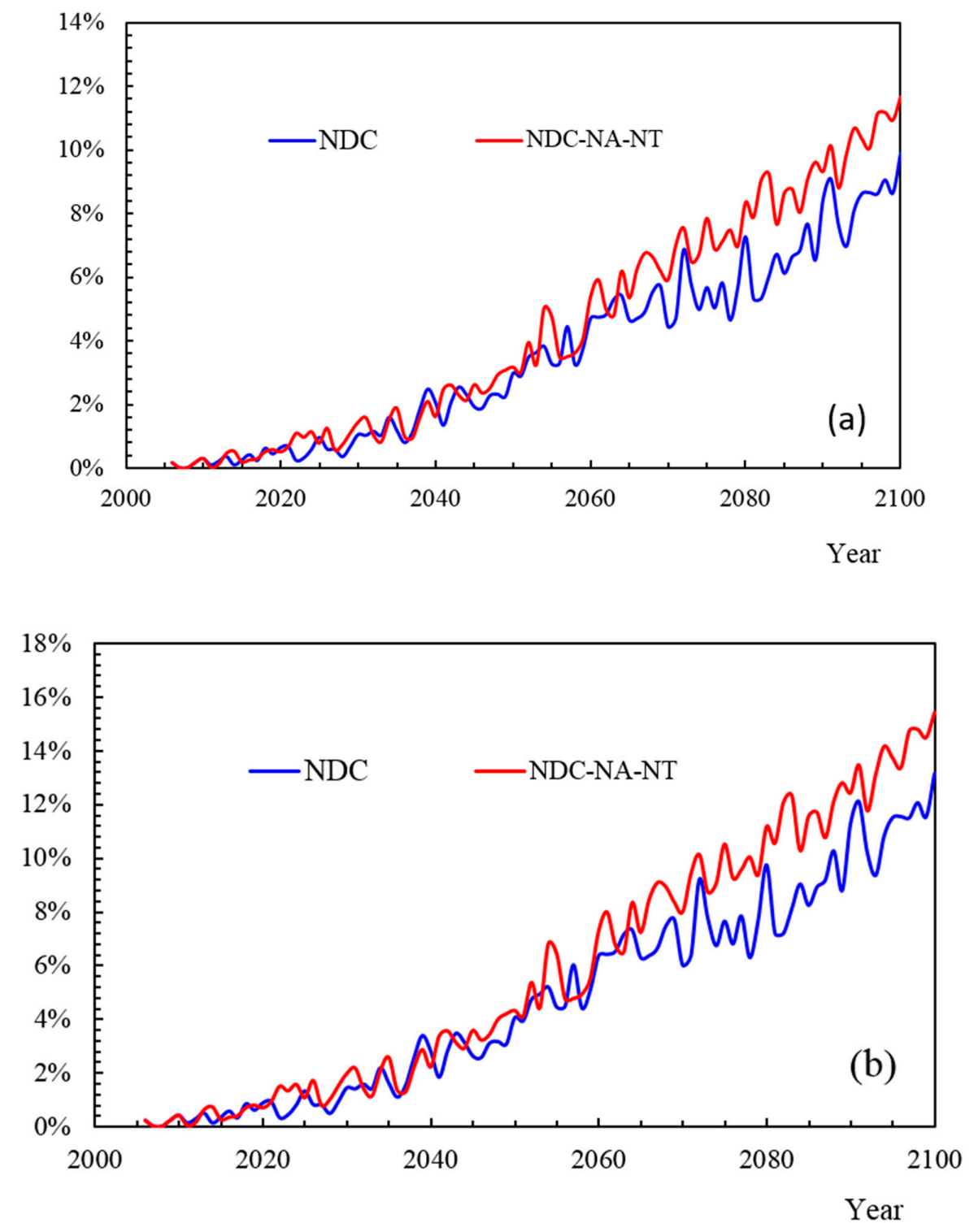

Figure 6. The economic loss of climate change under the NDC and NDC-NA-NT conditions: (a) the US, (b) China.

\section{Conclusions}

This paper investigates the impact of the US policies on climate change on global carbon emissions and climate change by combining the EMRICES model and Earth system model BNU-ESM. The US was assumed to follow or ignore the NDC with or without technological innovation. The EMRICES projection results showed that both the NDC target and technology innovation can effectively reduce the US carbon emissions. An additional 3.2 Gt $\mathrm{C}$ would be produced if the US does not meet the NDC and has no technological progress, compared to both situations in which the US follows its NDC or has implemented technological innovations at the end of the 21st century. This carbon emission gap could lead to an extra $62 \mathrm{ppm} \mathrm{CO}_{2}$ concentration and $0.6{ }^{\circ} \mathrm{C}$ increase in global temperatures by the end of the 21st century. In addition, it is suggested that both China and the US would suffer huge economic losses from climate change, particularly China. Furthermore, technological progress would reduce GDP losses by $2 \%$ if technological progression is not affected by the US climate policy. Our results also show that even if all the countries follow their most stringent NDC targets, it will be unlikely to keep the temperature rise below $1.5^{\circ} \mathrm{C}$ by the end of the 21 st century. 
These results reveal that more stringent emission reduction targets are required to control global warming below $1.5^{\circ} \mathrm{C}$, and that technological innovation is the key to controlling carbon emissions. Therefore, the US withdrawing from the Paris Agreement is not conducive to achieving the $1.5^{\circ} \mathrm{C}$ target, unless it promotes more positive technological innovations.

The policy implication of this study is that we should continue to emphasize low-carbon technology transfer, research, and development. Against the background of the US withdrawing from the Paris Agreement, the world should pay more attention to low-carbon technologies for developing countries, especially large emitters. At the same time, it is necessary to actively promote the application and development of low-carbon technologies in developed countries.

This study tries to quantitatively answer the climate change impact of a US withdrawal from the Paris Agreement from a natural science and social science perspective. Although this approach merges an economic model and an Earth system model, the results are based on a single economic model and only one Earth system model. Additionally, the results are calculated from offline modeling rather than online bidirectional coupling. Therefore, there are still uncertainties and areas that can be improved in future studies. It is necessary to use other economic models or multi-economic models to design emission scenario, or use other Earth system models and multiple model ensemble methods to solve similar issues. A fully coupled economic model and an Earth system model that considers the full interaction of the economic and natural systems could also reduce uncertainty.

Author Contributions: W.D. conceived and designed the experiments; S.Y. and C.L. performed the scenario and experiments; S.Y. C.L., J.C., D.T. and T.W. analyzed the data; Y.T. contributed analysis tools; S.Y. and C.L. wrote the paper. All authors read and approved the final manuscript.

Acknowledgments: This work was funded by the Major Research Development Program (No. 2016YFA0602700), the National Key Program for the National Nature Science Foundation of China (Grant No. 41330527), the National Natural Science Foundation of China (No. 41605036 and No. 41575001), the China Postdoctoral Fund (No. 2016M591108); the President's Youth Fund of Institutes of Science and Development, Chinese Academy of Sciences (No. Y7X1081Q01).

Conflicts of Interest: The authors declare no conflict of interest.

\section{References}

1. Meinshausen, M.; Meinshausen, N.; Hare, W.; Raper, S.C.; Frieler, K.; Knutti, R.; Frame, D.J.; Allen, M.R. Greenhouse-gas emission targets for limiting global warming to $2{ }^{\circ} \mathrm{C}$. Nature 2009, 458, 1158-1162. [CrossRef] [PubMed]

2. Mcglade, C.; Ekins, P. The geographical distribution of fossil fuels unused when limiting global warming to $2{ }^{\circ} \mathrm{C}$. Nature 2015, 517, 187-190. [CrossRef] [PubMed]

3. Huang, J.; Yu, H.; Dai, A.; Wei, Y.; Kang, L. Drylands face potential threat under $2{ }^{\circ} \mathrm{C}$ global warming target. Nat. Clim. Chang. 2017, 7, 417-422. [CrossRef]

4. Qi, S.; Li, Y. Threshold effects of renewable energy consumption on economic growth under energy transformation. China Popul. Resour. Environ. 2017, 15, 312-321. [CrossRef]

5. Bullock, J.A.; Haddow, G.D.; Haddow, K.S.; Coppola, D.P. Living with Climate Change; CRC Press: Boca Raton, FL, USSA, 2012.

6. Kristensen, P.M. After Abdication: America Debates the Future of Global Leadership. Chin. Polit. Sci. Rev. 2017, 2, 550-566. [CrossRef]

7. Mcguire, C.J.; Lynch, D. The Need for Environmental Justice Never Ends Because Externalities Persist. Soc. Sci. Electron. Publ. 2017, 10, 68-71. [CrossRef]

8. Mcguire, C.J. Uncommunicating Climate Change in the Trump Era: Influencing Public Policy by Attempting to Control the Message. Environ. Justice 2017, 10, 209-212. [CrossRef]

9. Takahashi, K.; Motoki, Y.; Tanimoto, T.; Kusumi, E.; Kami, M. Concerns ABOUT the Attitudes of President Trump Toward Isolationism, Vaccination, and Climate Change. Clin. Infect. Dis. 2017, 64, 1465-1466. [CrossRef] [PubMed]

10. Ladd, A.E.; York, R.; Ladd, A.E.; York, R. Hydraulic Fracking, Shale Energy Development, and Climate Inaction: A New Landscape of Risk in the Trump ERA. Hum. Ecol. Rev. 2017, 23, 65-79. [CrossRef] 
11. Watts, M. Cities spearhead climate action. Nat. Clim. Chang. 2017, 7, 537-538. [CrossRef]

12. Kristen, V.D.B. Where Oil is King. Soc. Sci. Electron. Publ. 2017, 85, 1631-1672.

13. Sanchez, D.L.; Sivaram, V. Saving innovative climate and energy research: Four recommendations for Mission Innovation. Energy Res. Soc. Sci. 2017, 29, 123-126. [CrossRef]

14. Seo, S.N. Beyond the Paris Agreement: Climate change policy negotiations and future directions. Reg. Sci. Policy Pract. 2017, 9, 121-140. [CrossRef]

15. Xing, R.; Hanaoka, T.; Kanamori, Y.; Masui, T. Greenhouse gas and air pollutant emissions of China's residential sector: The importance of considering energy transition. Sustainability 2017, 9, 614. [CrossRef]

16. Pan, X.; Chen, W.; Clarke, L.E.; Wang, L.; Liu, G. China's energy system transformation towards the $2{ }^{\circ} \mathrm{C}$ goal: Implications of different effort-sharing principles. Energy Policy 2017, 103, 116-126.

17. Wang, Z.; Wu, J.; Liu, C.; Gu, G. Integrated Assessment Models of Climate Change Economics; Springer: Berlin, Germany, 2017.

18. Donald Trump Executive Orders. 2017. Available online: https://www.federalregister.gov/executiveorders / donald-trump / 2017 (accessed on 1 June 2018).

19. The White House. An America First Energy Plan. Available online: https://www.whitehouse.gov/americafirst-energy (accessed on 1 June 2018).

20. Ji, D.; Wang, L.; Feng, J.; Wu, Q.; Cheng, H.; Zhang, Q.; Yang, J.; Dong, W.; Dai, Y.; Gong, D.; et al. Description and basic evaluation of Beijing Normal University Earth System Model (BNU-ESM) version 1. Geosci. Model Dev. 2014, 7, 2039-2064. [CrossRef]

21. Wu, Q.; Feng, J.; Dong, W.; Wang, L.; Ji, D.; Cheng, H. Introduction of the CMIP5 Experiments Carried out by BNU-ESM. Adv. Clim. Chang. Res. 2013, 9, 291-294.

22. Wei, T.; Yang, S.; Moore, J.C.; Shi, P.; Cui, X.; Duan, Q.; Xu, B.; Dai, Y.; Yuan, W.; Wei, X. Developed and developing world responsibilities for historical climate change and $\mathrm{CO}_{2}$ mitigation. Proc. Natl. Acad. Sci. USA 2012, 109, 12911-12915. [CrossRef] [PubMed]

23. Tian, D.; Dong, W.; Gong, D.; Guo, Y.; Yang, S. Fast responses of climate system to carbon dioxide, aerosols and sulfate aerosols without the mediation of SST in the CMIP5. Int. J. Climatol. 2016, 37, 1156-1166. [CrossRef]

24. Wei, T.; Dong, W.; Yuan, W.; Yan, X.; Yan, G. Influence of the carbon cycle on the attribution of responsibility for climate change. Sci. Bull. 2014, 59, 2356-2362. [CrossRef]

25. Wigley, T.M.L. MAGICC/SCENGEN 5.3: User Manual (Version 2); NCAR: Boulder, CO, USA, 2008.

26. Smith, S.J.; Wigley, T.M.L. Multi-Gas Forcing Stabilization with Minicam. Energy J. 2006, 27, $373-391$. [CrossRef]

27. Yang, S.; Dong, W.; Jieming, C.; Feng, J.; Yan, X.; Wei, Z.; Yuan, W.; Guo, Y.; Tang, Y.; Jiacong, H.U. A brief introduction to BNU-HESM1.0 and its earth surface temperature simulations. Adv. Atmos. Sci. 2015, 32, 1683-1688. [CrossRef]

28. Yang, S.; Dong, W.; Chou, J.; Feng, J.; Wei, Z.; Guo, Y.; Wen, X.; Wei, T.; Tian, D. Global warming projections using the human-earth system model BNU-HESM1.0. Sci. Bull. 2016, 61, 1833-1838. [CrossRef]

29. Di, T.; Yan, G.; Dong, W. Future Changes and Uncertainties in Temperature and Precipitation over China Based on CMIP5 Models. Adv. Atmos. Sci. 2015, 32, 487-496.

30. Wu, H. The impact of climate changes on mass events in China. Chin. J. Popul. Resour. Environ. 2016, 14, 11-15. [CrossRef]

31. Nordhaus, W.D.; Yang, Z. A regional dynamic general-equilibrium model of alternative climate-change strategies. Am. Econ. Rev. 1996, 741-765.

32. Nordhaus, W.D.; Boyer, J. Warming the World: Economic Models of Global Warming; MIT Press: Cambridge, MA, USA, 2000.

33. Nordhaus, W.D. The Challenge of Global Warming: Economic Models and Environmental Policy; Yale University: New Haven, CT, USA, 2007; Volume 4.

(C) 2018 by the authors. Licensee MDPI, Basel, Switzerland. This article is an open access article distributed under the terms and conditions of the Creative Commons Attribution (CC BY) license (http:/ / creativecommons.org/licenses/by/4.0/). 